\title{
Application of the antibiotic batumin for accurate and rapid identification of staphylococcal small colony variants
}

\author{
Larisa N Churkina', Svetlana I Bidnenko², Guido Lopes dos Santos Santiago ${ }^{3 *}$, Mario Vaneechoutte ${ }^{3}$, \\ Lilja V Avdeeva', Olga B Lutko² and Nadya M Oserjanskaja²
}

\begin{abstract}
Background: Staphylococcus aureus is a major human pathogen causing significant morbidity and mortality. The $S$. aureus colonies in osteomyelitis, in patients with cystic fibrosis and patients with endoprosthesis rejection frequently have an atypical morphology, i.e. staphylococcal small-colony variants, which form a naturally occurring subpopulation of clinically important staphylococci. Identification of these small colony variants is difficult, because of the loss of typical phenotypic characteristics of these variants.

We wanted to improve and simplify the diagnosis of staphylococcal infection using a diagnostic preparation, consisting of $5 \mu \mathrm{g}$ batumin paper disks. Batumin possesses a unique selective activity against all studied Staphylococcus spp., whereas all other species tested thus far are batumin resistant. We assessed the efficacy of the batumin diagnostic preparation to identify staphylococcal small colony variants, isolated from osteomyelitis patients.

Findings: With the batumin diagnostic preparation, all 30 tested staphylococcal small-colony variants had a growth inhibition zone around the disk of minimum $25 \mathrm{~mm}$, accordant with the inhibition zones of the parent strains, isolated from the same patients.

Conclusions: The batumin diagnostic preparation correctly identified the small-colony variants of S. aureus, S. haemolyticus and S. epidermidis as belonging to the genus Staphylococcus, which differ profoundly from parental strains and are difficult to identify with standard methods. Identification of staphylococcal small-colony variants with the batumin diagnostic preparation is technically simple and can facilitate practical laboratory work.
\end{abstract}

Keywords: Staphylococcus aureus, MRSA, Batumin, Staphylococcal small-colony variants

\section{Findings}

\section{Background}

Staphylococcus aureus is a major human pathogen causing significant morbidity and mortality in both community and hospital acquired infections [1]. The prevalence of methicillin-resistant S. aureus is increasing, and treatment has become more difficult due to the emergence of multidrug - resistant strains [2-4]. Infections caused by $S$. aureus are predominantly acute [5-7]. However, $S$. aureus can also cause chronic disease with recurrent infections as in osteomyelitis [8], in airway infections of

\footnotetext{
* Correspondence: guido.lopesdossantossantiago@ugent.be

${ }^{3}$ Laboratory Bacteriology Research, Department of Clinical Chemistry, Microbiology \& Immunology, Faculty of Medicine \& Health Sciences, Ghent University, Ghent, Belgium

Full list of author information is available at the end of the article
}

cystic fibrosis patients [9], or by colonizing tissues in endoprosthesis replacement, causing endoprosthesis rejection [10]. Agents of these infections present as atypical S. aureus forms, i.e. staphylococcal small-colony variants (SSCVs), which form a naturally occurring subpopulation of clinically important staphylococci and which can be isolated in pure culture.

Correct identification of bacterial small colony variants $(\mathrm{SCVs})$, specifically those of the genus Staphylococcus (SSCVs), faces some difficulties caused by the loss of typical phenotypic characteristics of these variants. Moreover, these SSCVs grow slowly, and as a result form small colonies, with reduction in toxin production and delayed coagulase activity [11]. It may be possible to improve accuracy of identification and simplify the diagnostics using antimicrobial agents with selective action 
against staphylococci. To this purpose, the antibiotic batumin with unique activity against all studied species of the genus Staphylococcus [4,12], has been used for the development of a in house diagnostic preparation, which consists of disks impregnated with $5 \mu \mathrm{g}$ of batumin. Previous results indicated the usefulness of the preparation for quick and reliable identification of isolates of the genus Staphylococcus with normal colony morphology [12-14]. As a result of successful testing of the batumin disks, a permit for the release of the new batumin diagnostic preparation was obtained and its application in clinical institutions of Ukraine was approved by The State Expert Center of the Ministry of Health of Ukraine (Protocol N P.09.01/03621 of September 6, 2001).

Here, we assessed the usefulness of the batumin diagnostic preparation for genus level identification of SSCVs.

\section{Results and discussion}

Culture of the samples and identification of the isolates with normal colony morphology, indicated the presence of Staphylococcus aureus, S. haemolyticus and S. epidermidis (Table 1).

All the colonies of the SSCVs were colorless, oxidase and catalase negative.

Gram staining revealed the presence of Gram-positive polymorphic cocci, both for the parental strains and the SSCVs.

For SSCVs, lecithinase activities were absent with exception of the S. aureus strains 143, 187/1, 1206 (weakly lecithinase positive) and coagulase activities were absent with exception of the $S$. aureus strains 127, 218, 389, 601 (weakly coagulase positive) (Table 1 ).

Although the tube coagulase test is considered as the gold standard in S. aureus identification [15], this study indicates that it is unreliable in the identification of SSCVs. The altered metabolism of SSCVs for carbohydrates, such as xylose, raffinose, melibiose, sucrose, maltose and lactose, as established here (Table 1), confirms previous findings [11].

Moreover, isolation and identification of atypical forms is further complicated by the fact that they are auxotrophic on haemin, amino acids and fatty acids [16]. To produce normal growth, various supplements, such as haemin and menadione, have to be added to the culture media.

The 17 SSCVs studied for auxotrophy could be classified into haemin dependent (S. aureus 18, 127, 187/2, 218, 280, 505, and S. epidermidis 233/1, 269, 349, 604), menadione dependent (S. aureus 187/1, 389 and S. epidermidis 151, 384, 385, 177) and thymidine dependent (only $S$. aureus 71).

Because the SSCVs lack a number of characteristics which otherwise enable identification with established phenotypic tests, we evaluated whether batumin impregnated disks were able to correctly identify the $30 \mathrm{SSCV}$ isolates. The presence of a growth inhibition zone of 17 $\mathrm{mm}$ or more around the disk was considered as evidence that the isolate belonged to the genus Staphylococcus, because we previously showed that the inhibition zones for 658 S. aureus, 152 S. epidermidis, 42 S. saprophyticus isolates and all isolates from 7 other Staphylococcus spp. were 17-29 mm, whereas all other Gram-positives (Dermacoccus spp. (5 isolates), Enterococcus faecalis (84), Kociura spp. (17), Kytococcus spp. (3), Microcococcus spp. (84), Planocococcus spp. (1), Streptococcus pyogenes (36) and viridans streptococci (30)) gave no inhibition zones, except for 10 isolates of Corynebacterium xerosis, which gave zones of $10 \mathrm{~mm}$ [12].

All 30 SSCVs gave a growth inhibition zone around the diagnostic disk of $25 \mathrm{~mm}$ and more, which can be interpreted as evidence that the isolates belong to the genus Staphylococcus (Figure 1).

Reliability of identification of the SSCVs by batumin impregnated disks as staphylococci was confirmed by molecular identification with tRNA-intergenic spacer length polymorphism analysis, shown previously to enable identification of staphylococci [17-19].

\section{Conclusions}

In conclusion, batumin impregnated disks correctly identified the SCVs of S. aureus, S. haemolyticus and S. epidermidis as staphylococci, although the SCVs differ profoundly from parental strains and are difficult to identify with standard methods. Identification of SSCVs by batumin is technically simple and can facilitate practical laboratory work.

\section{Methods}

Bone and muscle tissue biopsies, from patients with osteomyelitis in the Kyiv Institute of Traumatology and Orthopedics, Medical Academy of Sciences of Ukraine, were received as a part of standard medical care and this was approved by Ethics Committee of the Institute of Traumatology and Orthopedics, Medical Academy of Sciences of Ukraine (Protocol N2 of December 6, 2011).

The bone and muscle tissue biopsies were cultured onto Columbia agar with $5 \%$ washed sheep erythrocytes. A total of 30 staphylococcal SSCVs, i.e. slowly growing pinpoint colonies after 24-48 hours of incubation, were obtained as subpopulations of staphylococci with normal colony morphology. Identification of the staphylococci was carried out according to standard methods [20].

SSCVs were isolated on Columbia agar with $5 \%$ sheep blood, as pinpoint colonies $(0.1-0.3 \mathrm{~mm})$ after 48 hours of aerobic incubation at $37{ }^{\circ} \mathrm{C}$, among the more numerous colonies $(2-3 \mathrm{~mm})$ with normal Staphylococcus 
Table 1 Biochemical characteristics of staphylococcal small colony variants (SSCVs)

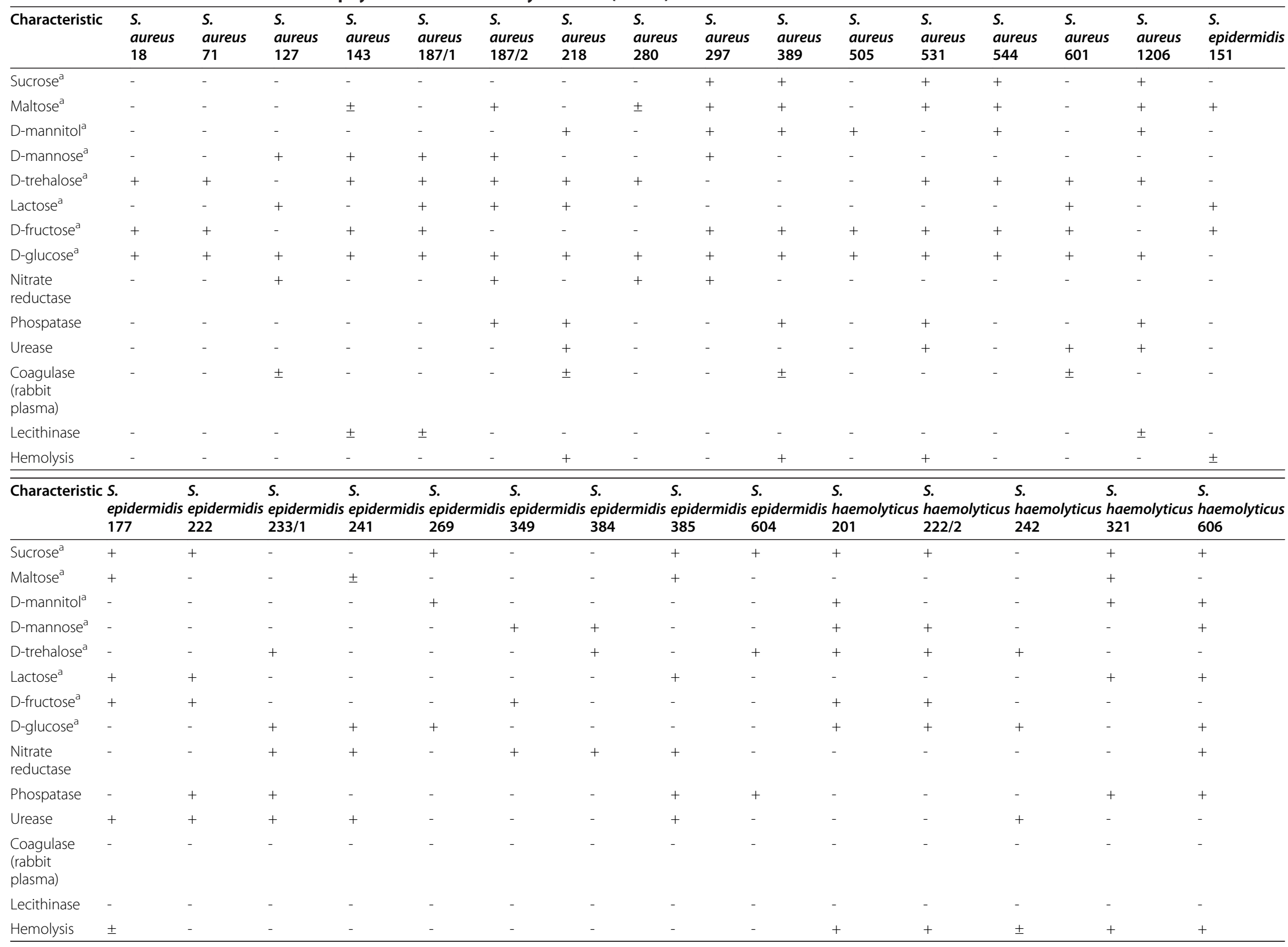




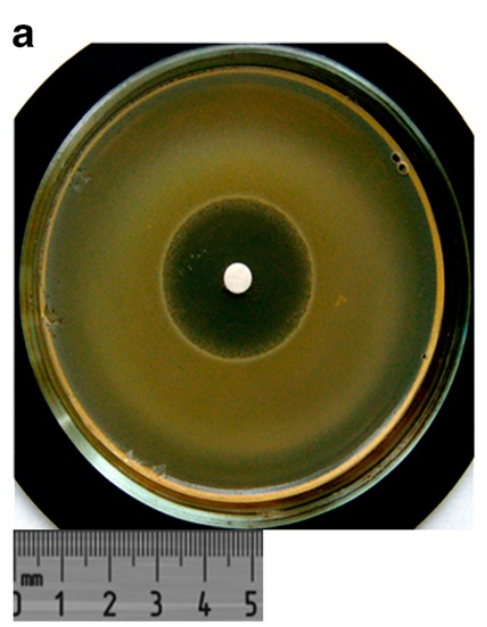

b

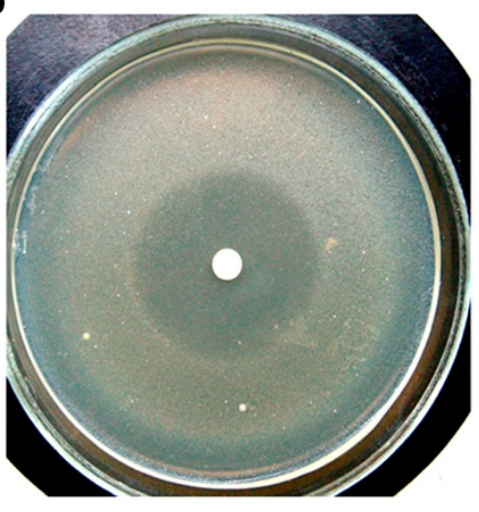

Figure 1 Identification with batumin of a) staphylococci with normal colony morphology and b) staphylococcal small colony variants.

morphology, considered as the staphylococcal parental isolates.

After re-isolation, colony morphology and pigmentation were observed on pepton agar plates $(10 \mathrm{~g}$ pepton agar, 5 g yeast extract, $5 \mathrm{~g} \mathrm{NaCl}, 1 \mathrm{~g}$ glucose and $15 \mathrm{~g}$ agar, per L of distilled water [21]. Acid production from carbohydrates and enzymatic activities were studied with API-Staph galleries (Biomérieux, Boxtel, The Netherlands). Fermentation of glucose was determined according to Hugh and Leifson [22], catalase activity by mixing a colony with a drop of $3 \% \mathrm{H}_{2} \mathrm{O}_{2}$, oxidase activity according to Faller and Schleifer [23], coagulase activity according to Sperber and Tatini [24], lecithinase activity according to the method of Akatov and Zueva [25], and hemolytic activity on agar supplemented with $5 \%(\mathrm{vol} / \mathrm{vol})$ washed rabbit erythrocytes.

For auxotrophy determination, the isolates were plated on Müller-Hinton agar (MHA) with a $2 \mu \mathrm{g}$ haemin disk, a $10 \mu \mathrm{g}$ menadione disk [26] or a $1 \mu \mathrm{g}$ thymidine disk.

Batumin is commercially available from Santa Cruz Biotechnology (Santa Cruz, CA) or Enzo Life Sciences (Antwerp, Belgium).

\section{Abbreviations}

SSCV: Staphylococcal small-colony variants; SCV: Small-colony variants; MHA: Müller-Hinton agar.

\section{Competing interests}

The authors declare that no competing interests exist.

\section{Authors' contributions}

$\mathrm{SB}, \mathrm{OL}, \mathrm{NO}$ : isolation of staphylococcal small colony variants (SSCVs) from osteomyelitis patients and their identificaton. LA: study of Sensitivity of staphylococcal clinical strains to wide spectrum of antibiotics. MV, GLdSS: part of the testing, providing with strains, identification of strains, writing. LC - Identification of small colony variants by batumin, article writing. All authors read and approved the final manuscript.

\section{Author details}

${ }^{1}$ Institute of Microbiology and Virology, National Academy of Sciences of Ukraine, Kyiv, Ukraine. ${ }^{2}$ Institute of Traumatology and Orthopedics, Medical Academy of Sciences of Ukraine, Kyiv, Ukraine. ${ }^{3}$ Laboratory Bacteriology Research, Department of Clinical Chemistry, Microbiology \& Immunology, Faculty of Medicine \& Health Sciences, Ghent University, Ghent, Belgium.

Received: 6 March 2012 Accepted: 30 June 2012

Published: 24 July 2012

\section{References}

1. Lovy FD: Staphylococcus aureus infections. N Engl J Med 1998, 399:520-532.

2. Santos Sanches I, Mato A, de Lencastre H, Tomasz ACEM/Net Collaborators, and International Collaborators: Patterns of multidrug resistance among clinical methicillin-resistant hospital isolates of coagulase-positive and coagulase-negative staphylococci collected in the international multicenter study RESIST in 1997 and 1998. Microb Drug Resist 2000, 6:199-211.

3. Chambers HF: Methicillin-resistant Staphylococcus aureus. Mechanisms of resistance and implications for treatment. Postgrad Med 2001, 109(Suppl 2):43-50.

4. Churkina LN, Bidnenko SI, Lutko OB, Avdeeva LV, Babenko LA: Study of the efficiency of antistaphylococcal antibiotic batumin against methicillin resistant strains of staphylococci. Antibiotics Chemother 2007, 52:29-34.

5. Wei HH, Wu KG, Sy LB, Chen CJ, Tang RB: Infectious endocarditis in pediatric patients: analysis of 19 cases presenting at a medical center. J Microbiol Immunol Infect 2010, 43:430-437.

6. Meyer E, Schwab F, Gastmeier P: Nosocomial methicillin resistant Staphylococcus aureus pneumonia - epidemiology and trends based on data of a network of 586 German ICUs (2005-2009). Eur J Med Res 2010, 15:514-524.

7. Lewis T, Chaudhry R, Nightingale P, Lambert P, Das I: Methicillin-resistant Staphylococcus aureus bacteremia: epidemiology, outcome, and laboratory characteristics in a tertiary referral center in the UK. Int J Infect Dis 2010, 15:131-135.

8. von Eiff C, Bettin D, Proctor RA, Rolauffs B, Lindner N, Winkelmann W, Peters G: Recovery of small colony variants of Staphylococcus aureus following gentamicin bead placement for osteomyelitis. Clin Infect Dis 1997, 25:1250-1251.

9. Kahl R, Herrmann M, Schulze Everding A, Koch HG, Becker K, Harms E, Proctor RA, Peters G: Persistent infection with small colony variants strains of Staphylococcus aureus in patients with cystic fibrosis. J Infect Dis 1998, 177:1023-1029.

10. Bidnenko SI, Lutko OB, Oserjanskaja NM, Churkina LN: Microflora of periprosthetic tissues according to aseptic instability of hip 
endoprosthesis and features of its sensitivity to antibiotics. Biomed Biosocial Anthropol 2010, 15:87-91.

11. McNamara PJ, Proctor RA: Staphylococcus aureus small colony variants, electron transport and persistent infections. Int J Antimicrob Agents 2000, 14:117-122.

12. Churkina L, Kiprianova E, Bidnenko S, Marchenko K, Artysuk E: Antibiotic batumin for diagnostics of staphylococci and treatment of Stapylococcus aureus nasal carriage. Lik Sprava 2009, 1(Suppl 2):61-67.

13. Smirnov W, Kiprianova EA, Gvozdiak OR, Churkina LN, Proskurakova NB, Kharchenko LA: The use of batumin-containing disks for the rapid identification of staphylococci. Zh Mikrobiol Epidemiol Immunobiol 1999 $5: 77-80$.

14. Smirnov W, Churkina LN, Nosenko GA, Bidnenko Sl, Artysiuk El, Pustovalova LI, Kiprianova EA, Garagulya AD: Efficacy of diagnostic disks with batumin in identification and indication of staphylococci. Lik Sprava Medicine 2002, 5-6:27-31.

15. Looney WJ: Small colony variants of Staphylococcus aureus. Br J Biomed SCi 2000, 57:317-322.

16. Balwit JM, van Langevelde P, Vann JM, Proctor RA: Gentamicin-resistant menadione and hemin auxotrophic: Staphylococcus aureus persist within endothelial cells. J Infect Dis 1994, 170:1033-1037.

17. Maes N, De Gheldre Y, De Ryck R, Vaneechoutte M, Meugnier H, Etienne J, Struelens MJ: Rapid and accurate identification of Staphylococcus species by tRNA intergenic spacer length polymorphism analysis. J Clin Microbiol 1997, 35:2477-2481.

18. Vaneechoutte $M$, Boerlin $P$, Tichy HV, Bannerman $E$, Jäger B, Bille J: Comparison of PCR-based DNA fingerprinting techniques for the identification of Listeria species and their use for atypical Listeria isolates. Int J Syst Bacteriol 1998, 48:127-139.

19. Supré K, De Vliegher S, Sampimon OC, Zadoks RN, Vaneechoutte M, Baele M, De Graef E, Piepers S, Haesebrouck F: Use of tRNA-intergenic spacer PCR combined with capillary electrophoresis to identify coagulasenegative Staphylococcus species originating from bovine milk and teat apices. J Dairy Sci 2009, 92:3204-3210.

20. Kloos WE, Schleifer KH: Genus IV. Staphylococcus. In Bergey's Manual of Systematic Bacteriology. Volume 2. Edited by Sneath PHA, Mair NS, Sharpe ME, Holt JG. Baltimore: Williams \& Wilkins; 1986:1013-1035.

21. Kloos WE, Tornabene TG, Schleifer KH: Isolation and characterization of micrococci from human skin, including two new species: Micrococcus lylae and Micrococcus kristinae. Int I Syst Bacteriol 1974, 24:79-101.

22. Hugh $\mathrm{R}$, Leifson $\mathrm{E}$ : The taxonomic significance of fermentative versus oxidative Gram-negative bacteria. J Bacteriol 1953, 66:24-26.

23. Faller A, Schleifer KH: Modified oxidase and benzidine tests for separation of staphylococci. J Clin Microbiol 1981, 13:1031-1035.

24. Sperber WH, Tatini SR: Interpretation of the tube coagulase test for identification of Staphylococcus aureus. Appl Microbiol 1975, 29:502-505.

25. Akatov AK, Zueva VS: Staphylococci systematics and the principles of species identification. In Staphylococci. Edited by Sobolev VP. Moscow: Meditsina Publishers; 1983:13-52.

26. Proctor RA, van Langevelde P, Kristjansson M, Maslov JN, Arbeit RD: Persistent and relapsing infections associated with small-colony variants of Staphylococcus aureus. Clin Infect Dis 1995, 20:95-102.

doi:10.1186/1756-0500-5-374

Cite this article as: Churkina et al: Application of the antibiotic batumin for accurate and rapid identification of staphylococcal small colony variants. BMC Research Notes 2012 5:374.

\section{Submit your next manuscript to BioMed Central and take full advantage of:}

- Convenient online submission

- Thorough peer review

- No space constraints or color figure charges

- Immediate publication on acceptance

- Inclusion in PubMed, CAS, Scopus and Google Scholar

- Research which is freely available for redistribution 